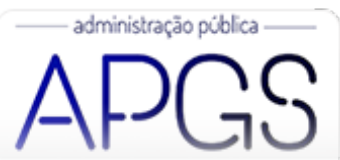

Administração Pública e Gestão Social ISSN: $2175-5787$

apgs@ufv.br

Universidade Federal de Viçosa

Brasil

\title{
Aplicação de um modelo para a análise de stakeholders: o caso da Secretaria de Turismo do Paraná
}

Amâncio-Vieira, Saulo Fabiano; Kramer Costa, Benny; Cintra, Renato Fabiano; Lebbos Favoreto, Ricardo Aplicação de um modelo para a análise de stakeholders: o caso da Secretaria de Turismo do Paraná

Administração Pública e Gestão Social, vol. 11, núm. 2, 2019

Universidade Federal de Viçosa, Brasil

Disponível em: http://www.redalyc.org/articulo.oa?id=351558326006

Esta obra está bajo una Licencia Creative Commons Atribución-NoComercial-SinDerivar 3.0 Internacional. 


\title{
Aplicação de um modelo para a análise de stakeholders: o caso da Secretaria de
} Turismo do Paraná

\author{
Applying a framework for stakeholder analysis: the case of the Paraná Department of Tourism \\ Aplicación de un modelo para la análisis de los stakeholders: el caso de la Secretaria de Turismo de Paraná
}

Saulo Fabiano Amâncio-Vieira

Universidade Estadual de Londrina, Brasil

saulo@uel.br

Benny Kramer Costa

Universidade de São Paulo, Brasil

bennycosta@yahoo.com.br

Renato Fabiano Cintra

Universidade Federal da Grande Dourados, Brasil

renatocintra@hotmail.com

Ricardo Lebbos Favoreto

Universidade Estadual de Londrina , Brasil

ricardo.favoreto@hotmail.com
Redalyc: http://www.redalyc.org/articulo.oa? id $=351558326006$
Recepção: 13 Abril 2017
Aprovação: 29 Dezembro 2017
Publicado: 01 Abril 2019

\section{Resumo:}

Pela Teoria dos stakeholders, a organização deve satisfazer não apenas acionistas, mas aqueles a ela vinculados também. Essa ampliação de enfoque induz ao desenvolvimento de trabalhos em setores até então pouco explorados. Objetiva-se, neste artigo, propor um modelo para a análise dos stakeholders, levando-se em conta as particularidades de um órgão público de turismo. A proposta embasa-se no caso da Secretaria de Turismo do Paraná. Modelos conceituais construídos anteriormente são revisados. A pesquisa foi realizada por meio de procedimentos qualitativos. O modelo apresenta uma perspectiva processual, que contempla as etapas: descrição do contexto institucional, identificação dos stakeholders, levantamento das suas características, verificação dos recursos disponíveis, análise da participação dos stakeholders, análise da perspectiva dos stakeholders e elaboração de plano de ação. Em relação aos modelos existentes, a proposta inova ao abranger o contexto institucional e mecanismos legais de legitimação da participação dos stakeholders e, diferentemente do usual, capta tanto a perspectiva da organização quanto a dos stakeholders.

\section{Abstract:}

According to the Stakeholder Theory, an organization must satisfy not only shareholders but also the parts that are related to it. This broadened approach leads to new researches in unexplored sectors. We propose in this paper a framework for stakeholder analysis, considering the specificities of a public organization. The proposal was grounded in the case of the Tourism Department of the State of Paraná, Brazil . Previously constructed conceptual models are reviewed. The research was conducted through qualitative analysis procedures. The model presents a procedural perspective, which includes the steps: description of the institutional context, identification of stakeholders, identification of its features, verification of the available resources, analysis of stakeholder participation,; analysis of stakeholders' perspectives and preparation of an action plan. Compared to existing models, the proposal innovates with the inclusion of institutional context and legal mechanisms to validate the participation of stakeholders. Also, unlike usual, it captures both the perspective of the organization and stakeholder.

KEYWORDs: Tourism, Stakeholder Analysis, Public Organizations, Conceptual Framework, Tourism Department .

\section{RESUMEN:}


En la Teoría de los Stakeholders, la organización debe satisfacer no sólo a los accionistas, sino también aquellos a ella vinculados. Esta ampliación del enfoque induce al desarrollo de trabajos en sectores hasta entonces poco explorados. El objetivo, en este artículo, es proponer un modelo para el análisis de los stakeholders, teniendo en cuenta las particularidades de un órgano público de turismo. La propuesta se basa en el caso de la Secretaria de Turismo del Paraná. Modelos conceptuales construidos anteriormente son revisados. La investigación fue realizada por medio de procedimientos cualitativos. El modelo presenta una perspectiva procesual, que contempla las etapas: descripción del contexto institucional, identificación de los stakeholders, levantamientos de sus características, verificación de los recursos disponibles, análisis de la participación de los stakeholders, análisis de la perspectiva de los stakeholders y elaboración del plan de acción. En relación a los modelos existentes, la propuesta innova al abarcar el contexto institucional y mecanismos legales de legitimación de la participación de los stakeholders y, diferentemente de lo que es habitual , capta tanto la perspectiva de la organización cuanto a de los stakeholders. Palavras clave: Turismo. Análisis de los Stakeholders. Organizaciones Públicas. Modelo Conceptual. Secretaria de Turismo. INTRODUÇÃO

\section{INTRODUÇÃO}

Nas últimas décadas, o termo stakeholder ganhou espaço em periódicos renomados no cená

Nas últimas décadas, o termo stakeholder ganhou espaço em periódicos renomados no cenário internacional (Miles, 2015), principalmente sob a perspectiva útil de abordar questóes das organizações e dar oportunidade para a realização de novas interpretações dessas questões (Harrison, Freeman, \& Abreu, 2015). $\mathrm{Na}$ literatura gerencial, a expressão disseminou-se especialmente após a publicação de Freeman (1984). Segundo definição clássica, stakeholder é "qualquer grupo ou pessoa cujos interesses podem afetar ou ser afetados pelas realizações dos objetivos de uma organização” (Freeman, 1984: 46). A suposição principal da Teoria dos Stakeholders é a ideia de que a eficácia organizacional é medida pela habilidade da organização de satisfazer não somente acionistas, mas também aqueles vinculados à organização, ou seja, que afetam ou são afetados pelos seus objetivos. Ampliando as possibilidades analíticas do campo da estratégia, a Teoria dos Stakeholders induziu ao desenvolvimento de trabalhos em setores e tipos organizacionais até então pouco explorados (Cintra, Ribeiro, \& Costa, 2015; Vieira, Costa, \& Cintra, 2012), a exemplo do caso apresentado neste artigo.

É simplista, hoje, conceber a organização privada como reinado privativo de seus proprietários. Cada vez mais, a organização privada é pressionada a atender a imperativos diversos, advindos de fontes diversas, que, não raro, contrapõem-se aos interesses imediatos dos proprietários. Da mesma forma, conceber a organização pública como abrigo de governos é absurdo. Não apenas pressões institucionais ordenadamente previstas como também pressões difusas, as quais emergem muitas vezes de modo desordenado, incidem sobre as organizações que integram o setor público. A sociedade, que envolve tanto organizações privadas quanto públicas tem-se tornado crescentemente complexa. Desprezar os interesses dos stakeholders inviabiliza, atualmente, a subsistência organizacional. Em setores que envolvem um coletivo muito extenso e plural de interessados, como o turístico, a abordagem dos stakeholders torna-se ainda mais relevante, como se torna, ainda, essencial contar com ferramentas, a exemplo da aplicação demonstrada neste artigo, que possibilitem a sistematização das análises.

A partir da década de 1990 o Brasil viveu grande expansão no setor turístico (Pimentel, Pimentel, \& Vidal, 2017). Nesse contexto, a criação no Brasil, em 2003, de um ministério exclusivo do turismo (o MTur), que, entre outras funções, tem por finalidade direcionar estrategicamente as políticas públicas de turismo (Virginio \& Ferreira, 2013), reflete a importância do setor no país, bem como inicia o processo de horizontalização do turismo no contexto nacional (Emmendoerfer, Soares, Silva, Lima, Gava, \& Monteiro, 2012), com ênfase no desenvolvimento turístico, na regionalidade (Emmendoerfer, Silva, \& Lima, 2011). Para o planejamento e para a implementação de ações, o ministério adotou como unidade analítica a região turística (Azevedo \& Rodrigues, 2015) ou indutores turísticos, como no Estado de Minas Gerais (Emmendoerfer et al., 2012). A edição dos planos nacionais de turismo, iniciada no mesmo ano, e a implementação das secretarias estaduais de turismo ratificam sua relevância. No Paraná, a Secretaria de Estado de Turismo (Setu) foi implementada com o objetivo de planejar o desenvolvimento do turismo 
no estado, pela estruturação de uma política estadual de turismo, associada ao trade turístico local (www.setu.pr.gov.br, recuperado em 14, setembro, 2009).

No turismo, a gestão de destinos tem sido o foco principal das pesquisas quando se trata da gestão como um todo (Santos, Leal, \& Panosso Netto, 2015). As pesquisas que conjugam Teoria dos Stakeholders e turismo têm escopos variados, entre os quais podemos listar turismo sustentável (Araújo, 2008); planejamento turístico (Brito, Breda, \& Costa, 2015; Coradini, 2011; Coradini, Costa, \& Vieira, 2012); meio ambiente (Delgado, 2011); gestão de hotelaria (Alves \& Wada, 2014; Koga \& Wada, 2013; Perera \& Jiménez, 2011); roteiro turístico (Manenti, 2008); destination branding (Costa \& Azevedo, 2015); relaçóes públicas (Soares, 2005); atividades estratégicas em órgãos públicos (Costa, Vieira, Boaventura, Coradini, \& Añez, 2009; Vieira, 2010; Vieira, Costa, \& Boaventura, 2011); competitividade e gerenciamento de destinos (Viera \& Hoffmann, 2009); estratégia organizacional e relacionamento (Junqueira \& Wada, 2011; Melo \& Régis, 2013); mapeamento de stakeholders (Cintra, Amâncio-Vieira, \& Costa, 2016; Cintra, AmâncioVieira, Gonçalves, \& Costa, 2015); tomada de decisão (Sabino, Procopiak, Hoffmann, \& Hoffman, 2005); stakeholders, eventos corporativos e hospitalidade (Guizi, Wada, \& Gândara, 2016); stakeholders e cocriação de valor (Zago \& Wada, 2013) e revisão de literatura e/ou método e/ou bibliometria (Cintra, Ribeiro, \& Costa, 2015; Costa, Vieira, \& Carmona, 2011; Vieira, Costa, \& Cintra, 2012).

Pela análise da literatura, nota-se haver ainda alguma insuficiência no que tange à análise de stakeholders em órgãos públicos de turismo. Vale ressaltar que as pesquisas em órgãos públicos do turismo tem caminhado no sentido de explorar a relação de intergovernabilidade dos entes (Emmendoerfer et al., 2012). Nesse contexto, a pesquisa relatada neste artigo explora, em profundidade e sob via bidirecional, as relações mantidas entre a Setu e seus principais stakeholders. Visa-se preencher lacunas do campo da estratégia, dada a carência de estudos sobre gestão turística e, especificamente, sobre a atuação de stakeholders (Vieira, Costa, \& Cintra, 2012).

Paralelamente, a pesquisa é importante para amparar a atuação de órgãos públicos na condução de políticas públicas de turismo. Relembre-se que a definição de uma política não é o mesmo que sua execução. A política pública compreende, além da sua decisão e proposição, sua implementação, execução e avaliação (Souza, 2006). No Brasil, não têm sido incomuns os exemplos de insucesso na condução de políticas públicas - definidas formalmente, mas não postas em prática de modo satisfatório. O setor turístico, envolvendo stakeholders os mais diversos, é palco recorrente de empreitadas improdutivas, que se perdem no emaranhado babélico de interesses igualmente diversos. O modelo utilizado para analisar a Setu pode, assim, subsidiar não apenas a definição (no que tange ao órgão em análise) como também a condução de políticas públicas, considerando-se, como requerido na atualidade, perspectivas múltiplas.

No caso em questão, captaram-se padrões que, juntamente com a literatura prévia, possibilitaram a construção de um modelo que apoia a análise de stakeholders. Pretende-se que o modelo subsidie, ainda que de forma adaptada, a análise de stakeholders de organizações públicas atuantes no setor turístico que, tal qual a Setu, operam em contextos marcados por altos graus de incerteza. A aplicação do modelo ao caso de que deriva, alternativamente ao detalhamento do exame do caso, permite que se aprofundem discussões sobre o próprio modelo também.

\section{ANÁLISE DE STAKEHOLDERS}

Sob o ponto de vista da organização, são stakeholders usuais proprietários, órgãos defensores dos consumidores, consumidores, competidores, mídia, empregados, grupos de interesses especiais, ambientalistas, fornecedores, governantes e organizações comunitárias locais (Freeman, 1984). Considerados os stakeholders, o processo de formulação de estratégias observa, para Freeman (1984), os seguintes pontos: análise de comportamento, explanação sobre comportamento, análise de coalização, estratégias genéricas (avaliação das forças estratégicas), geração de programas específicos para os stakeholders 
e programa de integração dos stakeholders. Os tipos de adequação que caracterizam o comportamento dos stakeholders representam-se, segundo Mitroff (1983), por categorias: propostas e motivações; recursos impostos, que podem ser material, simbólico, físico, status, informacional ou habilidade; conhecimentos específicos e opiniões; comprometimentos de ordem legal e de outros tipos; relacionamentos com outros stakeholders do sistema em virtude de poder, autoridade, responsabilidade e controle.

Para a identificação de stakeholders, Mitchell, Agle e Wood (1997) propõem um modelo sustentado em três dimensões: o poder do stakeholder de influenciar a empresa, sua legitimidade no relacionamento com a empresa e a urgência da reivindicação direcionada à empresa. $\mathrm{O}$ poder tende a derivar de três dimensões contextuais: poder normativo, poder coercitivo e poder utilitário. A legitimidade decorre da percepção de que as ações de uma entidade são desejáveis, apropriadas dentro de um sistema social. A urgência resulta de sensibilidade e criticidade em relação ao tempo. Associando os três atributos, Mitchell et al. (1997) enquadram os stakeholders no denominado salience model. Eles são agrupados em três classes: latentes, em espera e definitivos.

Para Reed et al.. (2009), a análise de stakeholders define aspectos de um fenômeno social e natural, identificando-se indivíduos, grupos e organizações que são afetados pela organização ou podem afetá-la e priorizando-se algumas partes em detrimento de outras no processo decisório. Os autores salientam a importância de duas das três abordagens propostas por Donaldson e Preston (1995), a normativa e a instrumental. A partir dos pressupostos indicados, propõem uma espécie de tipologia de análise de stakeholdersque consiste em três etapasconsistida em três etapas: identificação dos stakeholders, diferenciação entre os stakeholders e categorização, e investigação das relações entre os stakeholders.

Aplicações empíricas da análise de stakeholders proliferaram nas últimas décadas. Por um exercício preliminar de revisão da literatura, levantaram-se mais de cinquenta pesquisas. Seis enfoques analíticos parecem predominar:

O primeiro é o processo de identificação de stakeholders em diferentes contextos, bem como possíveis conflitos gerados. São exemplos: Pomeroy e Douvere (2008), Billgren e Holmen (2008) e Jepsen e Eskerod (2009). O segundo é o levantamento de interesses e expectativas dos stakeholders, a fim de se estabelecer o balanceamento entre atividades organizacionais e interesses sociais. São exemplos: Friedman e Mason (2004), Pomeroy e Douvere (2008) e Jepsen e Eskerod (2009). O terceiro é a compreensão da influência entre stakeholders. São exemplos: Yau, Chow e Sin (2007), Prell, Hubacek e Reed (2009) e Ferrary (2009).

O quarto enfoque é o processo decisório, abrangendo, entre outros elementos, a qualidade das decisões, a incorporação da perspectiva dos stakeholders, o envolvimento, a transparência e a diversidade de valores. São exemplos: Chase, Siemer e Decker (2002), Beierle (2002), Friedman e Mason (2004) e Schwarzkopf (2006). Questões referentes à legitimidade e ao poder dos stakeholders, desigualdade entre stakeholders e importância relativa do poder de tomada de decisão constituem o quinto enfoque. São exemplos: Billgren e Holmen (2008) e Hsieh (2009). O sexto enfoque constitui-se por questões referentes ao nível de relacionamento entre stakeholders e ambiente, à extensão de tais relações e sua evolução ao longo do tempo, à complexidade do sistema de relacionamento e às relações de dependência de recursos. São exemplos: Friedman e Miles (2002), Ferrary (2009) e Chung, Chen e Reid (2009).

De modo disperso, outros enfoques que aparecem são: participação e envolvimento dos stakeholders nos processos organizacionais, percepção dos stakeholders, fatores críticos de sucesso associados à gerência de stakeholders, subordinação da função-objetivo dos stakeholders à dos shareholders, características e definição de stakeholder (e.g., Varvasovszky \& Brugha, 2000; De Lopez, 2001; Vandekerckhouve \& Dentchev, 2005; Wong, 2005; Lamberg, Pajunen \& Parvinev, 2008; Web \& Raffaeli, 2008; Co \& Barro, 2009; Yang, Shen, \& Ho, 2009). 


\section{PROCEDIMENTOS METODOLÓGICOS}

A pesquisa utiliza-se de métodos qualitativos, com fins descritivos. Compõe-se de duas etapas: a primeira, exploratória; a segunda, de organização e aplicação do modelo. Na primeira, visou-se identificar e delinear a atuação dos stakeholders envolvidos no caso; na segunda, a partir do modelo construído, descrever como se dá essa atuação.

Minayo (1996) destaca que, por meio de estudos qualitativos, é possível uma melhor compreensão da complexidade dos fenômenos sociais, bem como dos seus significados. Esta pesquisa caracteriza-se como qualitativa, pois busca captar o fenômeno a partir da perspectiva das pessoas nele envolvidas, visando uma melhor compreensão da complexidade dos fenômenos sociais e seus significados. Triviños (1995) define um estudo descritivo como aquele em que o pesquisador pretende conhecer uma comunidade, seus traços característicos, seus valores, etc. Tais características fazem-se igualmente presentes nesta pesquisa, considerando que se visa analisar como ocorre a atuação dos stakeholders no desenvolvimento das atividades estratégicas da Setu.

A pesquisa possui, ainda, um caráter exploratório, em função de se desejar um melhor conhecimento e delineamento dos atores atuantes na atividade do turismo à luz do método de análise de stakeholders. Conforme indicado por Triviños (1995), um estudo exploratório permite ao investigador aumentar sua experiência sobre um determinado problema, de maneira que, ao conduzir um estudo desse tipo, o pesquisador aprofunde seu estudo sobre um determinado objeto ou situação, extrapolando as informações até então disponíveis.

O estudo de caso foi desenvolvido com a Setu. O estudo de caso caracteriza-se como uma estratégia de pesquisa adequada quando: (1) as questões de interesse do estudo referem-se ao como e ao porquê; (2) o pesquisador tem pouco controle sobre os acontecimentos; (3) o foco dirige-se a um fenômeno contemporâneo em um contexto natural (YIN, 2001). Segundo Merriam (1988), o estudo de caso é apropriado a pesquisas em que o interesse do pesquisador privilegia a compreensão dos processos sociais que ocorrem em determinado contexto ao invés da estreita relação entre variáveis. São todos fatores presentes neste estudo.

Yin (2001) alerta que a escolha pelo estudo de caso deve ser muito cuidadosa, uma vez que o caso deve ter características próprias que mereçam ser estudadas, como o órgão máximo do turismo de uma administração pública estadual. Sua escolha foi feita de forma intencional, levando-se em conta a facilidade de acesso e a importância desse organismo para o turismo e a economia regional. É importante salientar, em relação ao setor turístico, que este é muito importante para economia do estado e gerador significativo de emprego e renda. A análise do caso poderá subsidiar a análise de outros casos, igualmente relevantes para as regiões em que estão inseridos.

Visando-se estruturar a investigação (Miles \& Huberman, 1994), perseguiu-se as etapas preconizadas por Yin (2001), quais sejam: precisar a pergunta de pesquisa, levantar a literatura, organizar a fundamentação teórica e preparar um plano detalhado de pesquisa. Coletaram-se dados primários e secundários. Conforme recomendado (Gerring, 2007), buscou-se meios e fontes diversas. A coleta transcorreu por técnicas tradicionais, especialmente entrevistas e notas de campo (Godoy, 1995). Um roteiro semiestruturado, integrado por questões abertas (Gaskell, 2002), apoiou a condução das entrevistas. Informações relevantes obtidas por meio de análises documentais foram registradas em notas de campo.

Com vistas a obter robustez na fundamentação das ideias, praticou-se ao longo do período de coleta e análise, o movimento de triangulação, conforme recomendado em estudos de caso (Eisenhardt, 1989). Por esse movimento, buscou-se confirmar as evidências utilizando-se de fontes e dados diversos. A triangulação conferiu à interpretação dos dados tom dialético, especialmente quando da constatação de divergências entre os dados coletados por meio de entrevistas e os coletados por pesquisa documental. 
Analisou-se documentos que registram a história, que resgatam cenários e contextos e que retratam os acontecimentos relevantes, desde a criação do órgão seminal até a primeira década do século XXI , principalmente em termos de políticas para o setor turístico. Entre os textos analisados, destacam-se os contidos nos seguintes documentos: livros e outros textos a respeito da história do turismo no Paraná; informações sobre o histórico do Paraná divulgadas no site oficial do Estado; recortes de jornais; constituições federal e estadual; leis e decretos relacionados ao turismo no Brasil e no Paraná; planos plurianuais do turismo desenvolvidos pelos governos federal e estadual; relatórios técnicos e prestação de contas; atas e memórias de reuniões realizadas na Secretaria de Estado do Turismo, Conselho Consultivo, Câmaras Temáticas, entre outras.

A coleta de dados foi facilitada pelas visitas in loco realizadas e pela possibilidade de acesso ao sistema da Setu. Primeiramente, organizou-se todas as atas de reunião, tanto do Conselho quanto das Câmaras Temáticas, em ordem cronológica. Posteriormente, procedeu-se à classificação dos temas tratados em cada uma das reuniões, para facilitar a busca no processo de análise. Também em ordem cronológica foram organizadas as leis estaduais relacionadas ao turismo e suas estruturas de apoio. Notas de campo foram bastante utilizadas para registro de dados.

Para a realização das entrevistas, identificou-se, primeiro, o possível informante-chave, que participou da definição da agenda e da discussão dos critérios de escolha dos demais entrevistados. O informante era funcionário de carreira e já atuava no setor turístico desde antes da criação do formato atual da secretaria. A técnica de snowball foi utilizada na definição dos entrevistados seguintes. As entrevistas foram conduzidas entre 2009 e 2010. Foram entrevistadas e consultadas seis pessoas ligadas à Secretaria de Turismo: Secretário de Estado do Turismo, Diretor Geral da Setu, Coordenadora de Planejamento, Técnica da Coordenadoria de Assuntos Institucionais e Presidente e Diretor da Paraná Turismo, autarquia vinculada à Setu. Realizouse , ainda, entrevistas com pessoas ligadas aos seguintes stakeholders da Setu: Fecomércio, ABIH, Sebrae, $\mathrm{ABAV} / \mathrm{PR}$, Embratur e representante dos Gestores das Instâncias Regionais do Turismo.

A análise de dados pautou-se pela análise da enunciação (Minayo, 1996). Buscou-se mitigar eventuais vieses de interpretação, na medida em que levou-se em conta percepções diversas. Os dados foram analisados, primeiramente, em função de cada pergunta do roteiro e, em sequência, de forma agrupada, em função de conjuntos de perguntas relacionadas. A partir do método proposto por Minayo (1996, p. 206-208), a seguir apresenta-se uma sinopse dos trabalhos de análise realizados: 1. transcrição das entrevistas; 2. observância de que, para os propósitos desta pesquisa, a qualidade do material colhido é mais relevante do que a quantidade e de que cada fala é uma unidade básica; 3. realização de uma primeira leitura atenta e em profundidade de todas as falas transcritas, procurando contextualizar o que foi relatado pelos entrevistados; 4. realização de uma nova leitura do material; 5. separação das falas similares, juntando-as em blocos distintos, reservando espaços para anotações; 6 . busca do significado explícito de cada uma das falas transcritas; 7 . encerramento da análise quando os dados começaram a se repetir.

Cumpre salientar, por fim, que o modelo analítico foi desenvolvido ciclicamente - ou seja, o modelo não foi apenas aplicado ao caso em tela, mas também desenvolvido a partir do caso - com subsídio, portanto, tanto da literatura quanto dos dados coletados no campo. Assim, o levantamento bibliográfico viabilizou uma ideia prévia do modelo, que foi aprimorado de acordo com o material levantado diretamente do caso.

\section{DESENVOLVIMENTO DO MODELO}

O modelo representa uma perspectiva processual da análise de stakeholderse contempla tanto a perspectiva deles quanto da organização. Integra elementos básicos da Teoria dos Stakeholders e outros relacionados ao institucionalismo, à legitimidade e ao poder. Destacam-se os seguintes aportes teóricos: Meyer e Rowan (1977), Pfeffer e Salancik (1978), DiMaggio e Powell (1983), Mintzberg (1983), Freeman (1984), Scott (1987), Tolbert e Zucker (1996), Mitchell et al. (1997), De Lopez (2001), Beierle (2002), Chase, Siemer e 
Decker (2002), Friedman e Mason (2004), Schwarzkopf (2006), Lamberg et al. (2008), Pomeroy e Douvere (2008), Reed (2008), Reed et al. (2009). Toma-se como base o percurso sugerido por Chase, Siemer e Decker (2002), que prevê quatro etapas: análise da situação atual, esclarecimento do objetivo da instituição com a participação dos stakeholders, seleção do tipo de participação e seleção de um projeto em um contexto específico.

Sendo o modelo destinado a organizações públicas, a análise da situação atual foi expandida para um exame do contexto institucional histórico. O modelo contempla, ainda, questões ligadas ao balanceamento de interesses e à compreensão da forma como os participantes enxergam as decisões (Schwarzkopf, 2006) e ao monitoramento de poder, legitimidade e urgência (Mitchell, Agle, \& Wood, 1997; Friedman \& Mason, 2004).

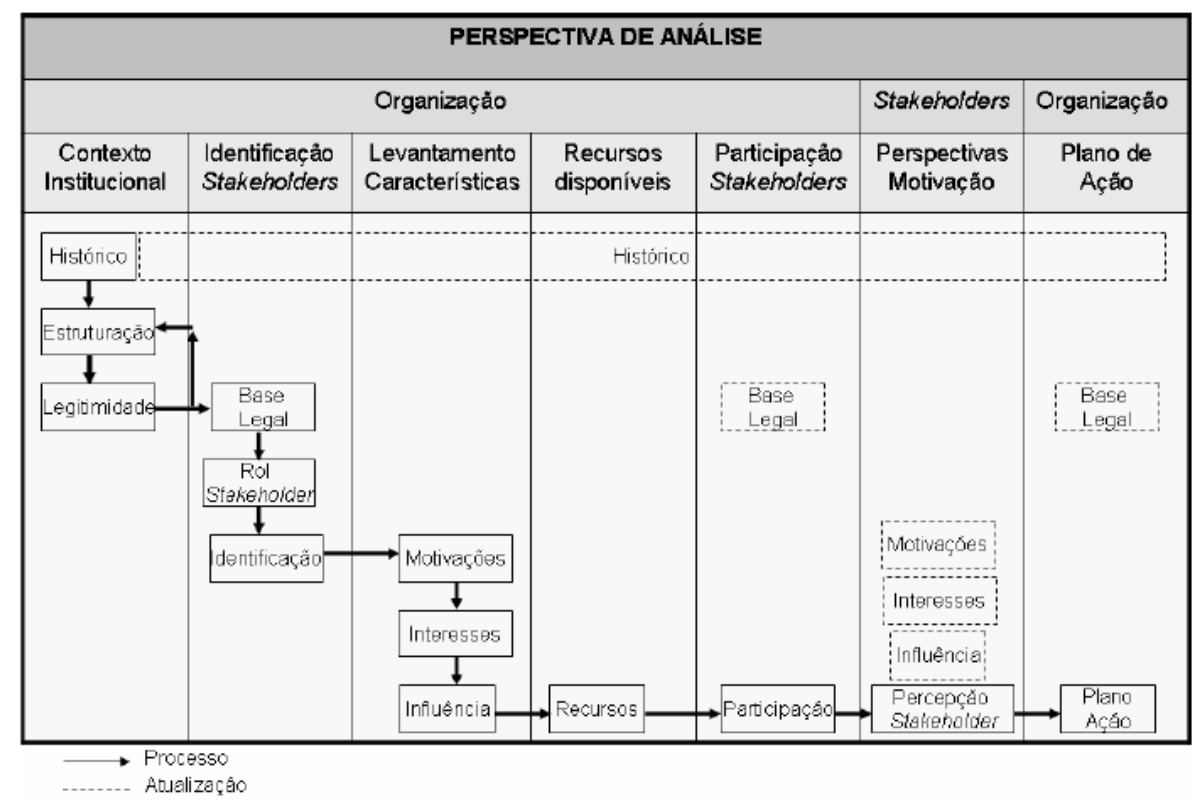

Figura 1: Modelo Conceitual

Fonte: elaboração própria.

Contexto institucional. Refere-se ao desenvolvimento histórico da organização, bem como ao seu processo de estruturação e à legitimidade da participação dos stakeholders junto à organização. Verifica-se, nesta fase, se o processo de institucionalização está sedimentado ou se ainda carece de continuidade, nos termos considerados por Meyer e Rowan (1977), DiMaggio e Powell (1983), Scott (1987) e Tolbert e Zucker (1996).

Identificação dos stakeholders. Verifica-se a existência de base legal que suporte os stakeholders. Identifica-se e descreve-se um rol de possíveis stakeholders. Na sequência, identifica-se os stakeholders que afetam a realização dos objetivos estratégicos da organização e avalia-se sua importância. Recomendações de Freeman (1984) e Reed et al. (2009), que sugerem a obtenção de respostas a questões do tipo “quem são?” e “como influenciam ou sofrem influência da organização?”, são abrangidas nesta fase.

Levantamento de características. Levanta-se as motivações e os interesses dos stakeholders no relacionamento com a organização, assim como os recursos de que dispõem e as influências sofridas. Procurase responder a questóes presentes em Freeman (1984), Bryson (1995), Joyce (1999) e Reed et al. (2009): “quais são seus interesses?”, “o que o motiva a participar da relação?”, “o que o motiva a envolver-se com aquele órgão?”, “de que a organização precisa?”, “de quem a organização precisa?”, “qual a importância daquilo e daqueles que a organização precisa?”.

Recursos disponíveis. Verifica-se os recursos de que os stakeholders dispõem e o interesse da organização neles. Identifica-se, ainda, possíveis relações de dependência, visando auxiliar na leitura das motivações dos 
stakeholders, conforme Lamberg et al. (2008) e Mintzberg (1983). Embasamento em Pfeffer e Salancik (1978), no que diz respeito ao poder e controle de recursos via normas e habilidades técnicas.

Participação dos stakeholders. Com base nas perspectivas legal e institucional, verifica-se a efetiva participação dos stakeholders no contexto da organização, cumprindo "obrigações legais", quando existentes. Parte-se do princípio de que uma participação intensa dos stakeholders contribui para o status de legitimidade do processo decisório (Beierle, 2002; Reed, 2008; Pomeroy \& Douvere, 2008).

Perspectivas da motivação. Analisa-se a perspectiva dos stakeholders. Identifica-se suas motivações, seus interesses, os recursos de que dispõem e as relações de poder. Deve-se, ao finalizar essas dessas identificações, ser capaz de elaborar uma análise comparada entre a perspectiva da organização e a do stakeholder, apontando-se eventuais diferenças (gaps) de visão. As questões a serem respondidas são as mesmas das fases 3 e 4, agora dirigidas aos stakeholders.

Plano de ação. Visa-se a elaboração de um plano de ação para atendimento dos gaps identificados. Nos pontos em que a visão da organização coincide com a do stakeholder, deve-se estruturar ações que reforçam tal convergência. Nos pontos divergentes, realiza-se ações que minimizem as diferenças. Compreender as ações dos stakeholders e planejar e implementar estratégias para minimizar gaps de expectativas pode ser fundamental para a gestão estratégica (De Lopez, 2001). Igualmente, pode contribuir para a construção de agendas de políticas públicas voltadas para o turismo, demanda próxima do que se apresenta em Nascimento, Simonian e Farias Filho (2016).

Alguns elementos, como o histórico e a base legal, devem ser continuamente atualizados, uma vez que mudanças no ambiente político-institucional tendem a afetar diretamente tanto a composição de stakeholders quanto as ações a serem praticadas. $\mathrm{Na}$ prática gerencial, a revisão desses elementos é imprescindível para que a organização atinja , de modo eficiente e eficaz, seus objetivos estratégicos.

\section{APLICANDO O MODELO}

\section{Contexto institucional}

O setor turístico paranaense ganhou espaço na política pública estadual na década de 1940, quando iniciouse o processo de formalização institucional. Esse processo pode ser descrito em cinco fases: na fase 1, sob atuação do Departamento de Turismo de Divulgação do Estado (1943-1968), criou-se o primeiro órgão colegiado do turismo estadual, iniciando a exploração comercial de ativos turísticos; na fase 2, sob atuação da Paranatur (1969-1989), criou-se o Conselho Paranaense de Turismo, já com controle estatal, ficando a cargo da Paranatur a exploração turística, a pesquisa e exploração de minérios e a fiscalização de algumas atividades setoriais; na fase 3, sob atuação da Fundação de Esporte e Turismo (Festur) (1989-1995), houve basicamente uma troca de entidades, sem alteração nas atribuições da Paranatur; na fase 4, criou-se a autarquia Paraná Turismo (a partir de 1995) e parte das atividades de exploração comercial e fiscalização deixaram de ser atribuição da Festur; na fase 5, criou-se a Setu (de a partir de 2002), entidade pela qual o Estado passou a definir políticas públicas para o setor. As fases 4 e 5 transcorrem atualmente concomitantemente.

Estabelecendo-se um paralelo com o contexto nacional, é possível notar a influência do contexto maior sobre os desdobramentos políticos do estado. Pimentel e Pimentel (2011), ao analisarem as fases da política brasileira voltada ao turismo, identificam cinco principais: a primeira, o Getulismo (1930-1955); a segunda, o período compreendido de Juscelino ao recuo do milagre econômico (1956-1979); a terceira, a redemocratização (década de 1980); a quarta, a liberalização (década de 1990); e a quinta, a recuperação do desenvolvimento (década de 2000).

A Setu foi criada tendo por objetivo definir diretrizes, propor e implementar as políticas de governo voltadas para o turismo, em todas as suas modalidades de promoção e, ainda, normatizar, fiscalizar e 
incentivar o turismo, como fator de desenvolvimento socioeconômico (www.setu.pr.gov.br, recuperado em 14, setembro, 2009). Beni (2008:102) destaca que "o turismo é uma atividade que requer intervenção proeminente do Estado pelo que representa em suas características fundamentais”. Talvez seja por isso que, "historicamente, o êxito do turismo em uma destinação depende da ação do Estado" (Ruschmann, 2010:150).

Verifica-se que, a partir de 2003, a atuação da Setu tem sido submetida a um maior controle social, dada a ampliação da participação da comunidade no planejamento, na execução e no acompanhamento de suas atividades. Credita-se esse aumento, principalmente, ao fato de ações democráticas proporcionarem maior autonomia política em níveis locais e regionais (Guinmarães, 2002). Seu planejamento estratégico é realizado por meio das coordenadorias de Relações Institucionais e de Planejamento. A operacionalização das ações estratégicas é definida pelo Plano de Desenvolvimento. Na instância programática, são as próprias coordenadorias que operacionalizam as atividades.

A participação dos stakeholders na Setu encontra-se ainda em processo de sedimentação, pelo qual se busca migrar da teorização à efetiva apresentação de resultados que possam ser relacionados à estrutura concebida. A inobservância do pilar cognitivo, importante componente no processo de institucionalização, poderá invalidar sua legitimidade. $\mathrm{O}$ arranjo institucional está, portanto, em uma fase delicada, cujo desfecho poderá confirmar a efetividade do atual modelo de relação entre a Setu e seus stakeholders ou apontar para lacunas que incitem o desenvolvimento de novos padrões de relações institucionais.

\section{Identificação dos stakeholders}

$\mathrm{Na}$ fase 1, 8 das 11 instituições integrantes do Conselho Estadual do Turismo eram entidades da sociedade civil. Na fase 2, quando foi criado o Conselho Paranaense do Turismo, verificou-se um ligeiro decréscimo da participação de entidades da sociedade civil, que passaram a ser 7 das 11 . Nesse período, o Estado orientase claramente para a exploração comercial dos ativos turísticos estaduais. Nas fases seguintes, mantém-se a mesma diretriz de controle governamental. Durante esse período, a Associação Brasileira de Agências de Viagens (ABAV), a Associação Brasileira da Indústria Hoteleira (ABIH) e a Associação Brasileira de Empresas de Eventos foram oficialmente inseridas no processo político estadual. Destaca-se, na fase 5, a criação, conforme orientação do MTur, do Conselho Consultivo de Turismo do Paraná, em formato de órgão colegiado.

Considerando-se que, no regime político brasileiro, a atividade pública é exercida via mecanismos normativos formais, percebe-se que a participação de entidades privadas no poder público foi, no setor turístico, relativamente baixa. Apenas em dois momentos - um ainda na década de 1950 e outro após 2003 - constatam-se expedientes protocolares voltados a garantir a representatividade da sociedade civil no poder público. Tal situação também foi elencada na gestão compartilhada entre o poder público e a sociedade civil no estado de Minas Gerais (Emmendoerfer, Silva, \& Lima, 2011).

Dos 44 membros do Conselho Consultivo, os entrevistados apontam apenas 8 como stakeholders fundamentais da Setu : o MTur, o Sebrae Paraná, o Governo do Estado, a Fecomércio, a ABAV, a ABIH, a Embratur, o conjunto de Gestores das Instâncias de Governança Regionais e dos Órgãos Municipais de Turismo.

\section{Levantamento de Caracteristicas e Recursos}

Os stakeholders mais relevantes são descritos, na sequência, em função dos recursos possuídos, dos interesses na Setu e da expectativa da Setu no relacionamento com o stakeholder. 
Saulo Fabiano Amâncio-Vieira, et al. Aplicação de um modelo para a análise de stakeholders: o caso...

Quadro 1: Descritivo do relacionamento dos stakeholders com a Setu

\begin{tabular}{|c|c|c|c|}
\hline Órgão & $\begin{array}{l}\text { Recursos } \\
\text { possuídos }\end{array}$ & $\begin{array}{l}\text { Interesse na } \\
\text { Setu }\end{array}$ & $\begin{array}{l}\text { Expectativa da } \\
\text { Setu }\end{array}$ \\
\hline MTur & $\begin{array}{l}\text { Recursos } \\
\text { financeiros, } \\
\text { técnicos, de } \\
\text { articulação } \\
\text { política, poder } \\
\text { de definição de } \\
\text { políticas, visão } \\
\text { descentralizada }\end{array}$ & $\begin{array}{l}\text { Implementaçăo, } \\
\text { no âmbito } \\
\text { estadual, de } \\
\text { políticas do } \\
\text { Plano Nacional } \\
\text { do Turismo e } \\
\text { das açóes } \\
\text { estrágicas } \\
\text { correspondentes }\end{array}$ & $\begin{array}{l}\text { Desenvolver o } \\
\text { Paraná como } \\
\text { destino turístico } \\
\text { e conseguir } \\
\text { apoio financeiro } \\
\text { para } \\
\text { implementar as } \\
\text { políticas } \\
\text { setoriais }\end{array}$ \\
\hline Sebrae/PR & $\begin{array}{l}\text { Recursos } \\
\text { financeiros, } \\
\text { humanos, } \\
\text { técnicos, de } \\
\text { networking e de } \\
\text { articulação }\end{array}$ & $\begin{array}{l}\text { Desenvolvimento } \\
\text { de propostas } \\
\text { regionais, } \\
\text { implementação } \\
\text { do projeto } \\
\text { Sebrae de } \\
\text { Turismo, } \\
\text { obtençăo de } \\
\text { legitimidade, } \\
\text { poder de } \\
\text { definição de } \\
\text { políticas } \\
\text { públicas e } \\
\text { atendimento à } \\
\text { Política Estadual } \\
\text { de Turismo }\end{array}$ & $\begin{array}{l}\text { Desenvolver o } \\
\text { Plano Estadual } \\
\text { de Turismo, } \\
\text { estabelecer } \\
\text { networking com } \\
\text { o empresariado, } \\
\text { formatar o } \\
\text { produto Paraná, } \\
\text { conseguir a } \\
\text { participação da } \\
\text { iniciativa } \\
\text { privada no } \\
\text { Turismo e obter } \\
\text { aporte de } \\
\text { recursos } \\
\text { financeiros. }\end{array}$ \\
\hline $\begin{array}{l}\text { Governo } \\
\text { do Estado }\end{array}$ & $\begin{array}{l}\text { Recursos } \\
\text { financeiros, } \\
\text { humanos ede } \\
\text { articulação } \\
\text { política. }\end{array}$ & $\begin{array}{l}\text { Uso do seu } \\
\text { conhecimento } \\
\text { técnico, para a } \\
\text { realização de } \\
\text { açôes em } \\
\text { parceria que } \\
\text { atendam ao } \\
\text { plano de } \\
\text { governo, } \\
\text { promovam } \\
\text { crescimento } \\
\text { econômico e } \\
\text { social, logrem } \\
\text { importância } \\
\text { institucional } \\
\text { (status) para o } \\
\text { governo e gerem } \\
\text { interaçăo } \\
\text { setorial via } \\
\text { Secretaria de } \\
\text { Estado }\end{array}$ & $\begin{array}{l}\text { Desenvolvimento } \\
\text { do Plano } \\
\text { Estadual, } \\
\text { reconhecimento } \\
\text { do turismo } \\
\text { como atividade } \\
\text { econômica, } \\
\text { conquista de } \\
\text { importância } \\
\text { institucional e } \\
\text { apoio técnico e } \\
\text { político }\end{array}$ \\
\hline Fecomércio & $\begin{array}{l}\text { Recursos } \\
\text { humanos, } \\
\text { financeiros, } \\
\text { networking e } \\
\text { poder }\end{array}$ & $\begin{array}{l}\text { Desenvolvimento } \\
\text { das açóes do } \\
\text { SENAC e do } \\
\text { SESC, obtenção } \\
\text { de legitimidade } \\
\text { e apoio político } \\
\text { e atendimento à } \\
\text { Política Estadual } \\
\text { de Turismo }\end{array}$ & $\begin{array}{l}\text { Desenvolver o } \\
\text { Plano Estadual } \\
\text { (qualificaçăo) e } \\
\text { obter recursos } \\
\text { financeiros e } \\
\text { legitimidade } \\
\text { junto ao } \\
\text { empresariado }\end{array}$ \\
\hline $\mathrm{ABAV}$ & $\begin{array}{l}\text { Recursos } \\
\text { técnicos }\end{array}$ & $\begin{array}{l}\text { Desenvolvimento } \\
\text { de novos } \\
\text { produtos para } \\
\text { comercialização } \\
\text { e para } \\
\text { realização de } \\
\text { açôes com seus } \\
\text { representados }\end{array}$ & $\begin{array}{l}\text { Desenvolver o } \\
\text { Plano Estadual } \\
\text { por meio de } \\
\text { promoçãa e } \\
\text { apoio à } \\
\text { comercializaçãa } \\
\text { e aproximar-se } \\
\text { dos seus } \\
\text { representados e } \\
\text { apoiá-los }\end{array}$ \\
\hline ABIH & $\begin{array}{l}\text { Recursos } \\
\text { técnicos e de } \\
\text { articulação } \\
\text { política }\end{array}$ & $\begin{array}{l}\text { Realizaçẫo de } \\
\text { açóes com seus } \\
\text { representados e } \\
\text { implementação } \\
\text { de açôes } \\
\text { estratégicas }\end{array}$ & $\begin{array}{l}\text { Aproximar-se } \\
\text { dos seus } \\
\text { representadose } \\
\text { apoiá-los }\end{array}$ \\
\hline Embratur & $\begin{array}{l}\text { Recursos } \\
\text { financeiros, } \\
\text { técnicose } \\
\text { humanos }\end{array}$ & $\begin{array}{l}\text { Desenvolvimento } \\
\text { do destino } \\
\text { Brasil } \\
\text { (internacional)e } \\
\text { obtençăo de } \\
\text { apoio para a } \\
\text { implementação } \\
\text { do Plano } \\
\text { Nacional de } \\
\text { Turismo } \\
\text { (promoção } \\
\text { internacional) }\end{array}$ & $\begin{array}{l}\text { Desenvolver o } \\
\text { destino Paraná e } \\
\text { seus produtos } \\
\text { no mercado } \\
\text { internacional e } \\
\text { obter apoio } \\
\text { financeiro e } \\
\text { técnico para o } \\
\text { desenvolvimento } \\
\text { de ações no } \\
\text { mercado } \\
\text { internacional }\end{array}$ \\
\hline $\begin{array}{l}\text { Instâncias } \\
\text { de } \\
\text { Governança } \\
\text { Regional e } \\
\text { Órgãos } \\
\text { Municipais } \\
\text { de Turismo }\end{array}$ & $\begin{array}{l}\text { Contato direto } \\
\text { com os atores } \\
\text { envolvidos nas } \\
\text { regióes } \\
\text { turísticas }\end{array}$ & $\begin{array}{l}\text { Consolidação } \\
\text { das instânias } \\
\text { como entidades } \\
\text { representativas } \\
\text { do turismo } \\
\text { regional }\end{array}$ & $\begin{array}{l}\text { Ter, em cada } \\
\text { regiấo, uma } \\
\text { entidade } \\
\text { representativa } \\
\text { para apoiar a } \\
\text { estruturação e a a } \\
\text { consolidação } \\
\text { dos produtos } \\
\text { turisticos e } \\
\text { formentar a } \\
\text { politica pública } \\
\text { de } \\
\text { regionalização } \\
\text { do turismo, } \\
\text { visando } \\
\text { transformar as } \\
\text { regiôes em } \\
\text { destinos } \\
\text { turísticos }\end{array}$ \\
\hline
\end{tabular}


Fonte: elaboração própria.

Tomando-se por base as proposições de Mitchell, Agle e Wood (1997), observa-se que MTur, Governo do Paraná, Sebrae e Fecomércio possuem os três atributos: poder, legitimidade e urgência. Quando isso ocorre, os gestores devem dar prioridade às suas reivindicações. Pode ocorrer que um stakeholder dominante adquira o atributo de legitimidade e se torne um stakeholder definitivo, fenômeno que pode vir a ocorrer com a Embratur, por exemplo. A ABAV e a ABIH são stakeholders que possuem legitimidade e urgência denominados, portanto, stakeholders dependentes, pois, devido à falta de poder, eles dependem de outros para que suas vontades sejam atendidas.

\section{Participação dos stakeholders}

Desde sua criação, a Setu foi gerida, pelo menos em princípio, de forma participativa. Os membros do Conselho Consultivo são regularmente convocados para participar de reuniões ordinárias e extraordinárias (quando necessário), nas quais se definem as atividades estratégicas da Setu. Como, no entanto, a mera presença nas reuniões colegiadas não implica necessariamente participação nas decisões, analisou-se todas as atas do Conselho Consultivo, referentes às reuniões ocorridas entre 2002 e 2009, com o objetivo de verificar a efetividade da participação dos membros presentes.

As primeiras atas demonstram engajamento dos membros, especialmente da Setu e da Fecomércio, na definição dos conselheiros e na elaboração do regimento da instituição. Nas reuniões seguintes, verificou-se que o Conselho passou a ter um caráter mais informativo e deliberativo, talvez porque questões de ordem técnica passaram a ser discutidas nas câmaras temáticas. Boa parte das atas registram falas do presidente do Conselho e, de acordo com o tema abordado, do coordenador da Câmara Temática, para relato de assuntos relacionados à correspondente esfera de atuação. As recorrentes solicitações dirigidas à Coordenadoria de Planejamento Turístico para explanar aos presentes demonstram o intuito de se envolver os participantes na formulação do planejamento das atividades da Setu.

As reuniões das Câmaras Temáticas não foram registradas em atas, motivo pelo qual foi necessário recorrer aos coordenadores técnicos das câmaras para resgatar os fatos. As reuniões ocorrem bimestralmente, a mesma frequência das reuniões do Conselho. Cada câmara possui uma Coordenação Geral e uma Coordenação Técnica, esta exercida por um membro vinculado à Setu. A participação dos membros nas câmaras varia de acordo com as características das demandas postas em exame. Quando são tratados na Câmara de Segmentação Turística assuntos relacionados ao turismo de aventura, a Associação Brasileira das Empresas de Ecoturismo e Turismo de Aventura tende a se envolver mais, uma vez que os assuntos estão relacionados a seu objetivo social.

Desde 2009 ocorre, ainda, uma reunião que precede a reunião do Conselho, da qual participa o chamado "Grupo dos Dez", composto pelos coordenadores, geral e técnico, das cinco câmaras temáticas. É nessas reuniões que se fecham as pautas das reuniões do Conselho. A reunião inicia-se com o relato de cada coordenador sobre os assuntos tratados em sua câmara e, posteriormente, definem-se os itens que integrarão a pauta da reunião do Conselho. Foram verificadas dificuldades com a Câmara Temática de Segmentação, que estava sem coordenação geral, e com a Câmara de Infraestrutura, que apresentava dificuldades de agenda da coordenadoria geral.

A necessidade de estender a ciência de alguns assuntos a todos os membros do Conselho motivou a criação do Informativo das Câmaras, que veicula um resumo dos principais assuntos abordados nas reuniões das câmaras. Recebidas as informações, a secretaria executiva do Conselho organiza-as e encaminha o informativo aos conselheiros.

Em média, a participação das entidades nas reuniões tem aumentado. No ano de criação da Setu, a presença média por reunião era de 17,67 participantes; em 2009, foi de 27 participantes. Esse crescimento não 
indica necessariamente um maior envolvimento nas operações do organismo. Em 2009, ainda se verificava um empenho relativamente tímido em atividades ligadas ao processo de definição e desenvolvimento das atividades turísticas do Estado. Apenas 19 entidades estiveram presentes em pelo menos $60 \%$ das reuniões. No primeiro ano da Setu, a média de presença dessas instituições foi de 68,76\%; em 2009, foi de 76,52\%, a maior média até então.

\section{Perspectivas da motivação dos stakeholders/plano de ação}

O Quadro 2 compara as expectativas da Setu e de alguns stakeholders, visando expor os aspectos a serem enfocados no desenvolvimento de novas ações. Enquanto as perspectivas baseiam-se nos dados coletados, as ações são sugestivas, apontadas apenas para demonstração . 
Quadro 2: Perspectivas para elaboração do plano de ação

\begin{tabular}{|c|c|c|c|}
\hline Entidade & $\begin{array}{l}\text { Perspectiva da } \\
\text { SETU }\end{array}$ & $\begin{array}{l}\text { Perspectiva dos } \\
\text { Stakeholders }\end{array}$ & Gaps/Plano de ação \\
\hline Sebrae/PR & $\begin{array}{l}\text { Parceria para } \\
\text { desenvolvimento } \\
\text { do Plano } \\
\text { Estadual de } \\
\text { Turismo, } \\
\text { networking com } \\
\text { empresariado, } \\
\text { formatação do } \\
\text { Produto Paraná, } \\
\text { participação da } \\
\text { iniciativa } \\
\text { privada e } \\
\text { angariação de } \\
\text { recursos } \\
\text { financeiros }\end{array}$ & $\begin{array}{l}\text { Parceria para } \\
\text { atendimento de } \\
\text { MPEs do setor e } \\
\text { busca de } \\
\text { legitimidade }\end{array}$ & $\begin{array}{l}\text { Convergência de } \\
\text { expectativas e focar } \\
\text { atividades que } \\
\text { priorizem MPEs do } \\
\text { setor turístico }\end{array}$ \\
\hline Fecomercio & $\begin{array}{l}\text { Parceria para } \\
\text { desenvolvimento } \\
\text { do Plano } \\
\text { Estadual, } \\
\text { angariação de } \\
\text { recursos } \\
\text { financeirose } \\
\text { conquista de } \\
\text { legitimidade } \\
\text { junto ao } \\
\text { empresariado }\end{array}$ & $\begin{array}{l}\text { Parceria para o } \\
\text { desenvolvimento } \\
\text { de açôes } \\
\text { conjuntas com o } \\
\text { objetivo de } \\
\text { atender ao } \\
\text { comércio, } \\
\text { implementação de } \\
\text { políticas publicas } \\
\text { setoriais e } \\
\text { relacionamento } \\
\text { técnico para } \\
\text { desenvolvimento } \\
\text { dos projetos }\end{array}$ & $\begin{array}{l}\text { Convergência de } \\
\text { expectativas e } \\
\text { implementar ações que } \\
\text { auxiliem empresas } \\
\text { comerciais do Paraná }\end{array}$ \\
\hline $\mathrm{ABAV}$ & $\begin{array}{l}\text { Parceria para } \\
\text { desenvolvimento } \\
\text { do Plano } \\
\text { Estadual } \\
\text { (promoção e } \\
\text { apoio à } \\
\text { comercialização), } \\
\text { aproximação e } \\
\text { apoio dos } \\
\text { representados }\end{array}$ & $\begin{array}{l}\text { Parceria entre os } \\
\text { setores público e } \\
\text { privado para } \\
\text { alavancar os } \\
\text { destinos turísticos }\end{array}$ & $\begin{array}{l}\text { Convergência de } \\
\text { expectativas }\end{array}$ \\
\hline $\mathrm{ABIH}$ & $\begin{array}{l}\text { Aproximação e } \\
\text { apoio dos } \\
\text { representados }\end{array}$ & $\begin{array}{l}\text { Parceria para } \\
\text { divulgar e } \\
\text { reivindicar } \\
\text { melhorias para o } \\
\text { setor hoteleiro, } \\
\text { atuando como } \\
\text { ponte de } \\
\text { comunicação } \\
\text { entre órgãos } \\
\text { públicos e } \\
\text { privados }\end{array}$ & $\begin{array}{l}\text { Convergência de } \\
\text { expectativas e } \\
\text { desenvolver ações para } \\
\text { o setor hoteleiro }\end{array}$ \\
\hline Embratur & $\begin{array}{l}\text { Parceria para } \\
\text { desenvolvimento }\end{array}$ & $\begin{array}{l}\text { Parceria para } \\
\text { promoção }\end{array}$ & $\begin{array}{l}\text { Convergência de } \\
\text { expectativas e reforçar }\end{array}$ \\
\hline
\end{tabular}

Saliente-se que as atividades a serem desenvolvidas pelos membros da Setu devem, antes de sua implementação, ser detalhadas, considerando-se suas possibilidades de recursos humanos, financeiros e de articulação. Sendo a Setu um órgão coordenador de esforços, a análise de stakeholders é uma importante ferramenta para mobilização das entidades de forma ordenada. 


\section{CONSIDERAÇÕES FINAIS}

A pesquisa realizada propõe um modelo de análise dos stakeholders utilizado para o caso de um órgão público ligado à atividade turística. A principal contribuição do modelo é conferir à análise de stakeholders uma visão processual, que se inicia na organização, passa pelos stakeholders e retorna à organização, ao culminar em um plano de ação. Destacam-se, nesta seção, primeiramente, alguns pontos referentes à Setu, levantados a partir da aplicação do modelo e, na sequência, as contribuições do modelo e as limitações de pesquisa e sugestões de estudos futuros.

A estruturação do setor turístico paranaense ganhou espaço em políticas públicas estatais a partir da década de 1940, quando se iniciou o processo de formalização institucional. A Setu protagoniza a quinta fase, vigente no momento da coleta de dados. No período compreendido entre 1943 e 1995, os stakeholders do órgão gestor do turismo eram internos ao poder público, instituições criadas pelo próprio Estado, cuja finalidade era a atuação de mercado. A partir de 1995, o cenário mudou, e setores da sociedade passaram a se envolver em órgãos colegiados. Constituído em 2003, o MTur convocou os órgãos públicos estaduais responsáveis para se organizarem conforme as diretrizes então instituídas. Os novos arranjos estaduais consolidaram, pela via normativa, a participação da sociedade na gestão turística. A análise de stakeholders passou a ser, assim, fundamental para a gestão do órgão.

Os stakeholders da Setu possuem motivações e interesses variados. Essa multiplicidade torna a gestão da Setu complexa. Ao mesmo tempo, sob a perspectiva setorial, tende a impulsionar os órgãos a operar em prol de um sistema. Quanto à participação das entidades na definição de políticas e estratégias para o setor, vale frisar que são poucas as entidades que se fazem presentes com maior frequência nas reuniões do Conselho. As participações nas reuniões tem aumentado gradativamente, mas, para que as políticas sejam fruto de um processo efetivamente participativo, é necessário um maior envolvimento das entidades no Conselho.

Como colocado, a principal contribuição do modelo utilizado é sua estrutura processual, que permite uma análise igualmente processual. Em relação aos modelos vigentes, adicionou-se elementos referentes ao contexto institucional, que, como demonstrado, são fundamentais para uma análise ambientada de stakeholders. Complementarmente, o modelo abrange questões relativas aos mecanismos legais de legitimação da participação dos stakeholders, o que pode ser especialmente útil para análises dirigidas a órgãos públicos, como a Setu, uma vez que a condução estratégica desses órgãos deve estar alinhada com regras formais de atuação. Ainda, o modelo conjuga duas perspectivas, a da organização em foco e a dos stakeholders. Associadas, essas perspectivas fornecem um retrato mais cabal do fenômeno, permitindo a proposição de planos de ação elaborados a partir dos gaps resultantes de possíveis diferenças entre as expectativas da organização e as expectativas dos stakeholders.

Entre as limitações da pesquisa, destacam-se os seguintes pontos: a despeito de ter por propósito a análise de stakeholders no contexto público, o modelo é construído a partir de elementos de outros modelos utilizados para análises no contexto privado.Disso podem decorrer (o que se perceberá com a reiteração de sua aplicação) eventuais insuficiências, sendo o intuito principal da pesquisa a proposição de um modelo, a análise de stakeholders em si carece de detalhamento, dependendo, portanto, de outras pesquisas que a esmiúcem. Cabe salientar ainda que o modelo apoia-se em análises de um caso único. $\mathrm{O}$ sistema federativo em função do qual o estado brasileiro está organizado gera e representa realidades deveras distintas. Sob pena de cair no simplismo, não se pode enxergar apenas um país sem considerar também o conjunto de 26 estados que o constituem. Além disso, há que se levar em conta que o pacto federativo nacional prevê níveis de governos cujas competências e jurisdições são diferentes. A Setu, por exemplo, atua de acordo com as atribuições que cabem a um órgão estadual, mas de um específico. Difícil conceber, portanto, uma cobertura genérica e indiscriminada do modelo apresentado. Qualquer aplicação sua há que admitir as especificidades contextuais do caso concreto. 
Como sugestões para pesquisas futuras, propõe-se: a replicação do modelo a outros órgão públicos estaduais de turismo, objetivando retroalimentar o modelo com eventuais ajustes; a representação do modelo em variáveis operacionalizáveis, de modo a possibilitar a realização de pesquisas quantitativas que propiciem generalizações e a realização de estudos cruzados, envolvendo outras regiões e países, a fim de se verificar o impacto de eventuais efeitos culturais ou geográficos na análise de stakeholders.

\section{REFERENNCIAS}

Alves, T., \& Wada, E. (2014). Os domínios da hospitalidade e a gestão de stakeholders em recrutamento e seleção estudo de casos múltiplos: Estanplaza, Travel Inn e Transamérica. Revista Ibero-Americana de Estratégia, 13(2), 99-116.

Araújo, L. (2008). Análise de stakeholders para o turismo sustentável. Caderno Virtual de Turismo, 8(1), 91-99.

Azevedo, R., \& Rodrigues, C. (2015). Políticas públicas e turismo rural: um estudo acerca das possibilidades e limitações no município de Apodi (RN). Caderno Virtual de Turismo, 15(2), 131-145.

Beierle, T. (2002). The quality of stakeholder-based decisions. Risk Analysis, 22(4), 739-749.

Beni, M. (2008). Análise estrutural do turismo. 13.ed. São Paulo: Senac SP.

Billgren, C., \& Holmen, H. (2008). Approaching reality: comparing stakeholder analysis and cultural theory in the context of natural resource management. Land Use Policy, 25(4), 550-562.

Brito, M., Breda, Z., \& Costa, C. (2015). Planejamento do turismo e stakeholders: abordagens, concepções e metodologias. Revista Iberoamericana de Turismo, 5(2), 140-154.

Bryson, J. (1995). Strategic planning for public and non-profit organization. San Francisco: Jossey-Bass Publishers.

Chase, L., Siemer, W., \& Decker, D. (2002). Designing stakeholder involvement strategies to resolve wildlife management controversies. Wildlife Society Bulletin, 30(3), 937-950.

Chung, W., Chen, H., \& Reid, E. (2009). Business stakeholder analyzer: an experiment of classifying stakeholders on the web. Journal of the American Society for Information Science and Technology, 60(1), 59-74.

Cintra, R., Amâncio-Vieira, S., Costa, B. (2016). Stakeholder theory e institucionalismo sociológico: complementações para análise do turismo local. Revista Iberoamericana de Turismo, 6(1), 165-186.

Cintra, R., Amâncio-Vieira, S., Gonçalves, L., Costa, B. (2015). Turismo local de Londrina-PR: análise a partir da teoria do stakeholder. Revista Contemporânea de Economia e Gestão, 13(2), 149-175.

Cintra, R., Ribeiro, I, \& Costa, B. (2015, outubro) Stakeholder theory e turismo: uma análise metodológica das publicações científicas no cenário brasileiro, 2000-2012. Anais do Seminário da Associação Nacional de Pesquisa e Pós-Graduação em Turismo, Natal, RN, Brasil, 12.

Co, H., \& Barro, F. (2009). Stakeholder theory and dynamics in supply chain collaboration. International Journal of Operations \& Production Management, 29(6), 591-611.

Coradini, C. (2011). Atuação e interação de stakeholders no planejamento turístico: um estudo de casos comparativos (Dissertação de mestrado). Universidade Nove de Julho, São Paulo, SP, Brasil.

Coradini, C., Costa, B., \& Vieira, S. (2012, agosto). Atuação e interação de stakeholders no planejamento turístico: o caso do município de Santo André/SP. Anais do Seminário da Associação Nacional de Pesquisa e Pós-Graduação em Turismo, São Paulo, SP, Brasil, 9.

Costa, A., \& Azevedo, A. (2015). Destination branding: o papel dos stakeholders na gestão da marca de destino - o caso da região do Douro (Portugal). Revista Brasileira de Gestão e Desenvolvimento Regional, 11(1), 182-205.

Costa, B., Vieira, S., \& Carmona, V. (2011, outubro). Stakeholders theory: um estudo bibliométrico da produção científica mundial no turismo. In Seminário da Associação Nacional de Pesquisa e Pós-Graduação em Turismo, Balneário Camboriú, SC, Brasil, 8.

Costa, B., Vieira, S., Boaventura, J., Coradini, C., \& Añez, M. (2009). A Influência dos stakeholders na estratégia de órgãos públicos: o caso da Diretoria de Turismo de Guarulhos/SP. Anais do Encontro de Estudos em Estratégia, Recife, PE, Brasil, 4. 
De Lopez, T. (2001). Deforestation in Cambodia: a stakeholder management approach. International Journal of Sustainable Development and World Ecology, 8(4), 380-394.

Delgado, A. (2011). Mapeamento de stakeholders nas áreas conexas de turismo e meio ambiente: um estudo em João Pessoa/PB (Dissertação de mestrado). Universidade Federal do Rio Grande do Norte, Natal, RN, Brasil.

DiMaggio, P., \& Powell, W. (1983). The iron cage revisited: institutional isomorphism and collective rationality in organizational fields. American Sociological Review, 48(2), 147-160.

Donaldson, T., \& Preston, L. (1995). The Stakeholder Theory of the corporation: concepts, evidences, and implications. Academy of Management Review, 20(1), 65-91.

Eisenhardt, K. M. (1989). Building Theories from Case Study Research. The Academy of Management Review, 14(4), 532-550.

Emmendoerfer, M., Soares, E., Silva, E., Lima, A., Gava, R., \& Monteiro, L. (2012). Desenvolvimento turístico regional e destinos indutores: um problema de intergovernabilidade no contexto público brasileiro? Anais do Encontro da Associação de Pós-Graduação e Pesquisa em Administração, Rio de Janeiro, RJ, Brasil, 36.

Emmerdoerfer, M., Silva, F., \& Lima, A. (2011). Evidências de inovação social na gestão pública do turismo em Minas Gerais - Brasil: o modelo de circuitos turísticos em análise. Pasos - Revista de Turismo y Patrimonio Cultural, $9(2), 397-410$.

Ferrary, M. (2009). A stakeholder's perspective on human resource management. Journal of Business Ethics, 87(1), $31-43$.

Freeman, R. (1984). Strategic management: a stakeholder approach. Massachusetts: Sage.

Friedman, A., \& Miles, S. (2002). Developing stakeholder theory. Journal of Management Studies, 39(1), 1-21.

Friedman, M., \& Mason, D. (2004). A stakeholder approach to understanding economic development decision making: public subsidies for professional sport facilities. Economic Development Quarterly, 18(3), 236-254.

Gaskell, G. (2002). Entrevistas individuais e grupais. In M. W. Bauer \& G. Gaskell (Orgs.), Pesquisa qualitativa com textos, imagem e som (pp. 64-89). Petrópolis: Vozes.

Gerring, J. (2007). Case Study Research. New York: Cambridge University Press.

Godoy, A. S. (1995). Pesquisa qualitativa: tipos fundamentais. Revista de Administração de Empresas, 35(3), 20-29.

Guinmarães, M. (2002). O debate sobre a descentralização de políticas públicas: um balanço bibliográfico. Organizações \& Sociedade, 9(23), 1-17.

Guizi, A., Wada, E., \& Gândara, J. (2016). Stakeholders, eventos corporativos e hospitalidade: estudos de casos múltiplos em Bourbon Hotéis e Resorts. Revista Iberoamericana de Turismo, 6(1), 53-72.

Harrison, J., Freeman, R., \& Abreu, M. (2015) Stakeholder theory as an ethical approach to effective management: applying the theory to multiple contexts. Review of Business Management, 17(55), 858-869.

Hsieh, M. (2009). Human centric knowledge seeking strategies: a stakeholder perspective. Journal of Knowledge Management, 13(4), 115-133.

Jepsen, A., \& Eskerod, P. (2009). Stakeholder analysis in projects: challenges in using current guidelines in the real world. International Journal of Project Management, 27(4), 335-343.

Joyce, P. (1999). Strategic management for the public services. Philadelphia: University Press.

Junqueira, R., \& Wada, E. (2011). Stakeholders: estratégia organizacional e relacionamento: estudo de casos múltiplos do setor hoteleiro. Revista Ibero-Americana de Estratégia, 10(3), 94-125.

Koga, E., \& Wada, E. (2013). Análise dos stakeholders e gestão dos meios de hospedagem: estudo de casos múltiplos na Vila do Abraão, Ilha Grande, RJ. Turismo em Análise, 24(1), 90-118.

Lamberg, J., Pajunen, K., \& Parvinen, P. (2008). Stakeholder management and path dependence in organizational transitions. Management Decision, 46(5-6), 846-863.

Manenti, D. Z. (2008). Identificação dos principais stakeholders e análise dos relacionamentos existentes no contexto do roteiro turístico da localidade de Ana Rech em Caxias do Sul-RS (Dissertação de mestrado). Universidade de Caxias do Sul, Caxias do Sul, RS, Brasil. 
Melo, P., \& Régis, H. (2013). Classificação dos laços entre gestores e stakeholders na rede dos pontos de cultura no grande Recife. Organizações \& Sociedade, 20(64), 75-96.

Meyer, J., \& Rowan, B. (1977). Institutionalized organizations: formal structure as myth and ceremony. American Journal of Sociology, 83(2), 340-363.

Merriam, S. B. (1988). Case Study Research in Education: a qualitative approach. San Francisco: Jossey-Bass.

Miles, M., \& Huberman, A. (1994). Qualitative data analysis: an expanded sourcebook (Cap. 2, pp. 16-39). Thousand Oaks: Sage.

Miles, S. (2015). Stakeholder theory classification: a theoretical and empirical evaluation of definitions. Journal Business Ethics, [Article in Press]: 1-23 [on-line].

Minayo, M. (1996). O desafio do conhecimento: pesquisa qualitativa em saúde. São Paulo: Hucitec.

Mintzberg, H. (1983). Power in and around organizations. New Jersey: Prentice Hall, Inc.

Mitchell, R., Agle, B., \& Wood, D. (1997). Toward a theory of stakeholder identification and salience: defining the principle of who and what really counts. Academy of Management Review, 22(4), 853-886.

Mitroff, I. (1983). Stakeholders of the organizational mind: toward a new view of organizations policy making. San Francisco: Jossey-Bass Publishers.

Nascimento, V., Simonian, L., \& Farias Filho, M. (2016). Política pública de turismo do Amazonas a partir do Modelo de Fluxos Múltiplos. Caderno Virtual de Turismo, 16(1), 141-157.

Perera, A., \& Jiménez, M. (2011). La gestión de las relaciones com los grupos de interés: un análisis exploratorio de casos en el sector hotelero español. Estudios y Perspectivas en Turismo, 20(4), 753-771.

Pfeffer, J., \& Salancik, G. (1978). The external control of organizations: a resource dependence perspective. New York: Harper and How.

Pimentel, M., \& Pimentel, T. (2011). A trajetória das políticas públicas de turismo brasileiras 1930-2010. Anais do Encontro da Associação de Pós-Graduação e Pesquisa em Administração, Rio de Janeiro, RJ, Brasil, 35

Pimentel, T., Pimentel, M., \& Vidal, J. (2017). Políticas públicas de turismo numa perspectiva normativa comparada: os casos de Brasil e Espanha. Pasos - Revista de Turismo y Patrimonio Cultural, 15(2), 293-310.

Pomeroy, R., \& Douvere, F. (2008). The engagement of stakeholders in the marine spatial planning process. Marine Policy, 32(5), 816-822.

Prell, C., Hubacek, K., \& Reed, M. (2009). Stakeholder analysis and social network analysis in natural resource management. Society \& Natural Resources, 22(6), 501-518.

Reed, M. (2008). Stakeholder participation for environmental management: a literature review. Biological Conservation, 141(10), 2417-2431.

Reed, M., Graves, A., Dandy, N., Posthumus, H., Hubacek, K., Morris, J., Prell, C., Quinn, C., \& Stringer, L. (2009). Who's in and why? A typology of stakeholder analysis methods for natural resource management. Journal of Environmental Management, 90(5), 1933-1949.

Ruschmann, D. (2010). Turismo e planejamento sustentável: a proteção do meio ambiente. 16.ed. Campinas/SP: Papirus.

Sabino, B., Procopiak, J., Hoffmann, R., \& Hoffmann, V. (2005). A importância dos stakeholders na tomada de decisão das pousadas de Bombinhas. Turismo: Visão e Ação, 7(2), 341-354.

Santos, G., Leal, S., Panosso Netto, A. (2015). O Brasil na literatura internacional de turismo: análise das publicações em idioma inglês. Revista Brasileira de Pesquisa em Turismo, 9(3), 459-478.

Schwarzkopf, D. (2006). Stakeholder perspectives and business risk perception. Journal of Business Ethics, 64(4), 327-342.

Scott, W. (1987). The adolescence of Institutional Theory. Administrative Science Quarterly, 32(4), 493-511.

Soares, T. (2005). As relações públicas em organizações do setor turístico: uma visão de gestores da cidade de LondrinaPR (Dissertação de mestrado). Universidade do Vale do Itajaí, Balneário Camboriú, SC, Brasil.

Souza, C. Políticas públicas: uma revisão de literatura. Sociologias, 8(16), 20-45, 2006. 
Triviños, A. N. S. (1995). Introdução à pesquisa em ciências sociais: a pesquisa qualitativa em educação: o positivismo, a fenomenologia, o marxismo. São Paulo: Atlas.

Tolbert, P., \& Zucker, L. (1998). A institucionalização da teoria institucional. In S. R. Clegg, C. Hardy \& W. R. Nord (Orgs.). Handbook de Estudos Organizacionais (Vol. 1, pp. 196-226). São Paulo: Atlas.

Vandekerckhove, W., \& Dentchev, N. (2005). A network perspective on stakeholder management: facilitating entrepreneurs in the discovery of opportunities. Journal of Business Ethics, 60(3), 221-232.

Varvasovszky, Z. \& Brugha, R. (2000). Stakeholder analysis: a review. Health Policy and Planning, 15(3), 239-246.

Vieira, S. (2010). Dinâmica de atuação dos stakeholders em atividades estratégicas: a experiência da SETU (Tese de doutorado). Universidade Nove de Julho, São Paulo, SP, Brasil.

Vieira, S., Costa, B., \& Boaventura, J. (2011). Análise de stakeholders aplicada em órgãos públicos: o caso da Secretaria de Estado do Turismo do Paraná. Revista de Ciências da Administração, 13(31), 81-110.

Vieira, S., Costa, B., \& Cintra, R. (2012). Stakeholders analysis: um novo campo de pesquisa no turismo. Revista Brasileira de Pesquisa em Turismo, 6(2), 21-33.

Viera, E., \& Hoffmann, V. (2009, setembro). Avaliação de competitividade e gerenciamento de destinos: uma aplicação no sul do Brasil. Anais do Seminário da Associação Nacional Pesquisa e Pós-Graduação em Turismo, São Paulo, SP, Brasil, 6.

Virginio, D. \& Ferreira, L. (2013). Gestão pública do turismo: uma análise da política de regionalização no período 2004-2011 no Rio Grande do Norte, Brasil. Caderno Virtual de Turismo, 13(2), 162-182.

Webb, T., \& Raffaelli, D. (2008). Conversations in conservation: revealing and dealing with language differences in environmental conflicts. Journal of Applied Ecology, 45(4), 1198-1204.

Wong, B. (2005). Understanding stakeholder values as a means of dealing with stakeholder conflicts. Software Quality Journal, 13(4), 429-445.

Yang, J., Shen, G., \& Ho, M. (2009). Exploring critical success factors for stakeholder management in construction projects. Journal of Civil Engineering and Management, 15(4), 337-348.

Yau, O., Chow, R., \& Sin, L. (2007). Developing a scale for stakeholder orientation. European Journal of Marketing, 41(11-12), 1306-1327.

Yin, R. (2001). Estudo de caso: planejamento e métodos. Porto Alegre: Bookman.

Zago, A., \& Wada, E. (2013). Dinâmica de stakeholders e cocriação de valor em museus: um olhar inicial. Revista Ibero-Americana de Estratégia, 12(2), 274-298.

\section{BY-NC-ND}

